\title{
Evaluation of corrosion product formed on carbon steel in recycled sour water of overhead system
}

\author{
Azzura Ismail*, Syamimi Mahari', Firdaus Shamsuddin ${ }^{1}$, Norhariti Hasan ${ }^{2}$, \\ Nursyazwani ramli ${ }^{2}$
} ${ }^{1}$ Faculty of Mechanical and Manufacturing Engineering, Universiti Tun Hussein Onn Malaysia, Batu Pahat, 86400,
MALAYSIA

${ }^{2}$ Malaysian Refining Company Sdn Bhd (Formally known as PETRONAS), Sg Udang, Melaka, MALAYSIA

*Corresponding Author

DOI: https://doi.org/10.30880/ijie.2019.11.07.013

Received 09 October 2019; Accepted 25 October 2019; Available online 15 November 2019

\begin{abstract}
Corrosion rate of carbon steel in recycled sour water, dilution sour water and $3.5 \% \mathrm{NaCl}$ was investigated by electrochemical test and immersion. The results revealed as the corrosion product developed on carbon steel, the corrosion rate was linearly decreased in both solutions. The sour water properties were investigated using Inductively Coupled Plasma-Mass Spectrometry (ICP-MS) to detect metal elements. The properties of corrosion product have been characterized using Scanning Electron Microscopy (SEM) and while the mechanical properties of carbon steel were identified using hardness test. SEM reveals corrosion products of patch pattern with some spiky flower. Corrosion properties of carbon steel in sour and seawater was performed using Electrochemical testing with Tafel plot while weight loss was identified by immersion test. It was observed that as immersion time increased, corrosion rate decreased due to passivation effect by corrosion product.
\end{abstract}

Keywords: Corrosion, carbon steel, electrochemical test, immersion, SEM

\section{Introduction}

The crude distillation unit (CDU) is where the incoming crude oil distils into various fractions of different boiling ranges and further in the other refinery processing units [1]. CDU is a complex process in the field of separation which produces a wide range of products at different stages under different conditions [2]. The products of the process were heavy naphtha, kerosene, diesel, atmospheric gas oil and reduced crude. Corrosion attack at CDU overhead system is catastrophic if precaution is never taken to monitor corrosion attack and continues to be a significant integrity and reliability concern within the refining industry [3]. For many crude units, good desalting and caustic injection practices are the first lines of defense in managing overhead corrosion issues, while injection of inhibitors is also applied in order to keep corrosion rate to a minimum. Properties of sour water entering overhead of CDU unit is one of the main variables that impact the corrosion rates [4]. Normal practices are to inject neutralizer into the vapor line before water injection point. But the concern is, does the neutralizer in wash water line really help to reduce corrosion in crude column overhead system.

Corrosion issues in the overhead system of crude distillation units (CDUs) are very common in the petrochemical industry. The corrosion attack might cause not only in the form of aqueous corrosion owing to hydrogen chloride that origins from hydrolysis of inorganic chlorides in crude pre-heat and furnace, but might due to ammonium and fouling of other heating systems [5]. The complexity of the process involved and media makes the overhead system one of the most susceptible to corrosion in the distillation units [6]. It also explains why corrosion in overhead is frequently observed not only on the assets but also on the media, which may attribute to the aggressiveness of corrosion activity. 
Whilst these mitigation strategies are very effective in mitigating corrosion, traditional corrosion monitoring and control relies on periodic sampling and analysis of overhead sour water to determine the corrosive nature of the process such as properties of corrosion products and effect of deterioration on base metal (carbon steel). This can contribute to indication of magnitude of corrosion activity by the measurement of carbon steel in sour water.

\section{Experimental Procedures}

All The research starts with identifying the properties of corrosion products formed on carbon steel, which had been immersed in sour water. This sour water can be considered as wastewater, which has been used in the refinery to cool down the overhead system of CDU units [5]. This research aims to identify either this so-called 'wastewater' can be used again as water wash in overhead systems of CDU rather than discharge to the water treatment process. The material used in this research is carbon steel, which is the same material as CDU overhead. The composition of the carbon steel used in this research is shown in table 1 . The sour water was supplied by the refinery industry which has been used as cooling water in the tower head. The objective of this research is to identify the properties of this water to be used again as a water wash in the overhead system of CDU.

\subsection{Sample preparation}

For corrosion measurement, carbon steel was used as working electrodes. Prior to the electrochemical test, the samples were embedded in resin with an identified exposed area in contact with the electrolyte. Next, the working electrode surface was mechanically grinding and polishing using 400-1200 emery papers ended with diamond paste [7]. The shining sample was then washed with distilled water and ultrasonically cleaned with acetone.

\subsection{Experimental setup}

Corrosion evaluation was determined by immersion and electrochemical analysis. The working electrode (carbon steel) was immersed in $3.5 \% \mathrm{NaCl}$, sour water and dilutions of sour water which contain $60 \%$ of sour water with $40 \%$ distilled water for a period of time from 7-35 days and weight loss were taken weekly. For corrosion rate properties, the experiments were conducted in a conventional three-electrodes cell $(50 \mathrm{~mL})$ using a WONATECH potentiostat/galvanostat. A silver/silver chloride $(\mathrm{Ag} / \mathrm{AgCl})$ and a platinum rod were used as a reference and counter electrodes, respectively. All the potentials quoted in this work are referred to as this electrode.

Table 1 - Composition of carbon steel

\begin{tabular}{cccccc}
\hline Material & \multicolumn{5}{c}{ Composition (\%) } \\
\cline { 2 - 6 } & $\mathbf{C}$ & $\mathbf{M n}$ & $\mathbf{F e}$ & $\mathbf{C u}$ & $\mathbf{Z n}$ \\
\hline Carbon steel & & & & & \\
AISI 2010 & 0.184 & 0.662 & 97.75 & 0.043 & 0.037 \\
\hline
\end{tabular}

Table 2 - Analysis of as-received sour water

\begin{tabular}{lc}
\hline \multicolumn{1}{c}{ Analysis } & Result \\
\hline Dissolve oxygen $(\mathrm{mg} / \mathrm{L})$ & 2.56 \\
$\mathrm{pH}$ & 6.7 \\
Salinity $(\mathrm{ppm})$ & 165 \\
\hline
\end{tabular}

\section{Results and discussion}

\subsection{Properties and composition of sour water}

The sour water is considered as waste water containing sulfides and chlorides, among other components. It can be considered a very harmful electrolyte to metallic structure especially to carbon steel. By exposing the structure to untreated sour water will results in high corrosion rates leading to failures and material drainage and spilling. The first step for this research is setting a scene by identifying the properties of as-received sour water from the industry. This untreated sour water was identified its oxygen level, $\mathrm{pH}$ and salinity as its benchmarking properties. The results in Table 2 revealed that the properties of this sour water are are not suitable to be used as wash water since its properties not achieve the Petronas's Technical Standard (PTS) for wash water. The $\mathrm{pH}$ of wash water must be between 7-9 and salinity should be less than $100 \mathrm{ppm}$ as set by PTS. Result for vigorous elements found in sour water that can initiate corrosion as shown in Table 3. These elements are not recommended to be contained in sour water as they can be agents to accelerate corrosion attack. The high $\mathrm{pH}$ of the desalter wash water may create emulsion problems in the desalter vessels. The temporary emulsion phase can be stabilized, resulting in water-carryover into the desalted crude 
oil. Some refiners add acids like diluted sulphuric acid to control the $\mathrm{pH}$ of the desalter wash water. However, the high degree of fluctuations in the acids present in the overhead system sometimes make it difficult to optimize the neutralizer and filming amine demand, which can result in elevated levels of corrosion being observed.

Table 3 - Table composition of sour water from ICP-MS

\begin{tabular}{ccccc}
\hline Element & Mean $(\mathbf{m g} / \mathbf{L})$ & Net intensity & \%RSD & Present \\
\hline $\mathrm{C}$ & 0.0000 & 321.7000 & 53.08 & $\mathrm{~N}$ \\
$\mathrm{C}$ & 0.0060 & 475.1667 & 38.43 & $\mathrm{~N}$ \\
$\mathrm{P}$ & 0.0020 & 74.9000 & 271.14 & $\mathrm{~N}$ \\
$\dot{Z}$ & 0.0003 & 139.8 & 7.02 & $\mathrm{~N}$ \\
\hline
\end{tabular}

\subsection{Immersion test of AISI 1020 in different solutions}

Understanding of the kinetics and mechanism of the corrosion activity required to understand the properties of corrosion products formed on carbon steel in sour media before it can be used as water wash in CDU head panel systems. This experimental step was run to identify the corrosion rate of carbon steel in a sour medium as compared to seawater and dilute sour water. The rate will later be compared with carbon steel in $3.5 \% \mathrm{NaCl}$ and dilute sour water. At the end of the immersion, a conclusion can be made that corrosion product are weakly adherent and porous which controlled by iron dissolution and atomic hydrogen diffusion. The dilution of sour water was prepared in a ratio of $60 \%$ sour water with $40 \%$ of distilled water.

Table 3 - Weight loss for immersion test

\begin{tabular}{cccc}
\hline Period (day) & $\mathbf{3 . 5 \%}$ NaCl (\% wt loss) & Sour water (\% wt loss) & Dilution (\% wt loss) \\
\hline 7 & $0.030(0.24)$ & $0.039(0.31)$ & $0.0262(0.20)$ \\
1 & $0.044(0.36)$ & $0.050(0.39)$ & $00344(0) 7)$ \\
2 & $0.067(0.54)$ & $0.059(0.46)$ & $00403(037)$ \\
$\mathbf{1}$ & $0.068(0.55)$ & $0.073(0.60)$ & $00436(037)$ \\
$\mathbf{n}$ & $0.071(0.56)$ & $0.089(0.73)$ & $0.0716(0.58)$ \\
\hline
\end{tabular}

The initial weight was 12.51 (in $3.5 \% \mathrm{NaCl}$ ), 12.82 in sour water and $11.96 \mathrm{~g}$ in dilution $11.96 \mathrm{~g}$

Table 4 - Electrochemical parameters of solutions with and without (wo) oxygen (deaerated)

\section{Solution}

Tafel parameters

$3.5 \% \mathrm{NaCl}$

Sour Water

Dilution

\begin{tabular}{|c|c|c|c|c|c|c|}
\hline & $\mathbf{w}$ & With & $\mathbf{w}$ & With & $\mathbf{w}$ & With \\
\hline$E_{\text {corr }}(V)$ & -0.77 & -0.51 & -0.64 & -0.64 & - & -0.64 \\
\hline Ba(V/decade) & 0.11 & 0.053 & 0. & 0. & 0.033 & 0.050 \\
\hline$B c($ V/decade $)$ & 0.061 & 0.069 & 0.434 & 0. & 0.087 & 0.069 \\
\hline$i_{\text {corr }}\left(\mu A / \mathrm{cm}^{2}\right)$ & 1.42 & 1.633 & 3. & 0.496 & 1. & 2. \\
\hline$R_{P}(K \Omega)$ & 12.10 & 7. & 6 & 2. & 6 & 5. \\
\hline $\mathrm{CR}(m m / y r)$ & 0.21 & 0. & 0. & 1 & $\begin{array}{l}0 . \\
22\end{array}$ & $\begin{array}{l}0 . \\
72\end{array}$ \\
\hline
\end{tabular}

\subsection{Corrosion determination in solutions of with and without oxygen content}

The corrosion rate of carbon steel in every solution (electrolyte) was identified in with and without oxygen content. For the solution without oxygen content (deaerated), nitrogen was purged in to purge out the oxygen content in the solutions. Then the electrochemical analysis was run by selecting Tafel plot to determine corrosion reactions. The 
temperature was kept at $27^{\circ} \mathrm{C}$ and $\mathrm{pH}$ value measured was 6 to 7 (neutral). The results of electrochemical parameters were listed in table 4.

Weight (wt) loss increased as the immersion period is increased in every solution. The weight loss was highest in sour water elucidate that the material thinning very fast as the immersion period increased as shown in figure 1 . The exponential plot revealed the same conclusion in every solution. Corrosion rate calculated by electrochemical analysis revealed the sour water with oxygen content gives the highest corrosion rate followed dilution solutions and $3.5 \% \mathrm{NaCl}$ for both with and without oxygen (figure 2). This revealed that sour water with acidic $\mathrm{pH}$ gives tremendous corrosion rate as compared to other solutions. The corrosion product produced during this corrosion activity was evaluated for morphology and composition using SEM and EDX analysis.

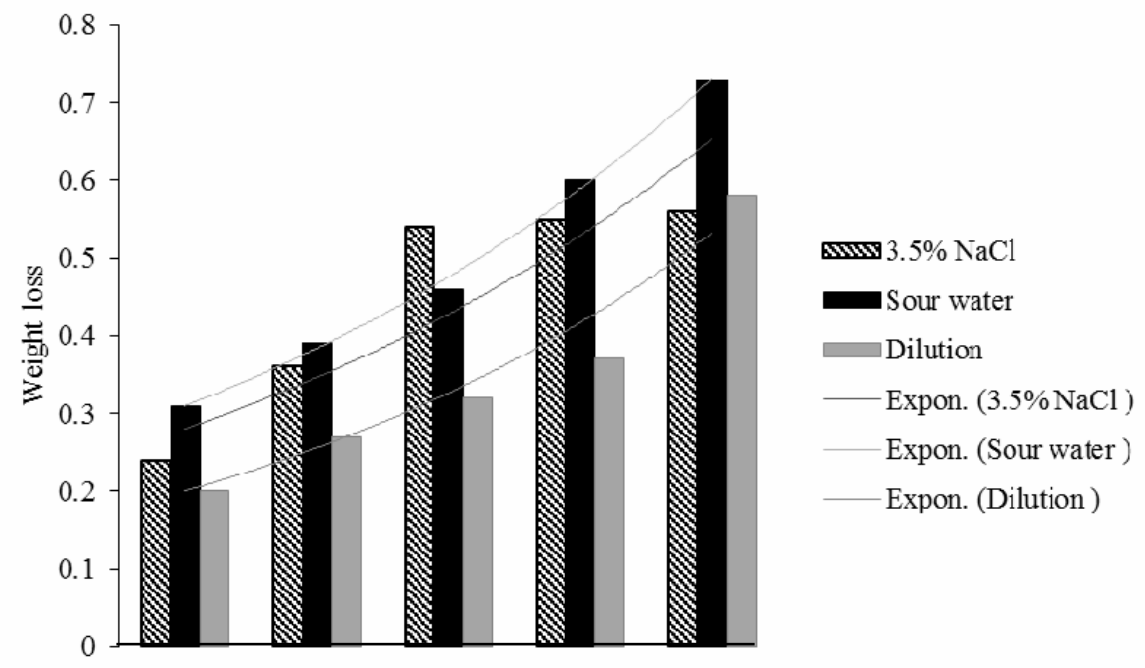

Immersion period

Fig. 1 - Weight loss of carbon steel in every solution by immersion technique

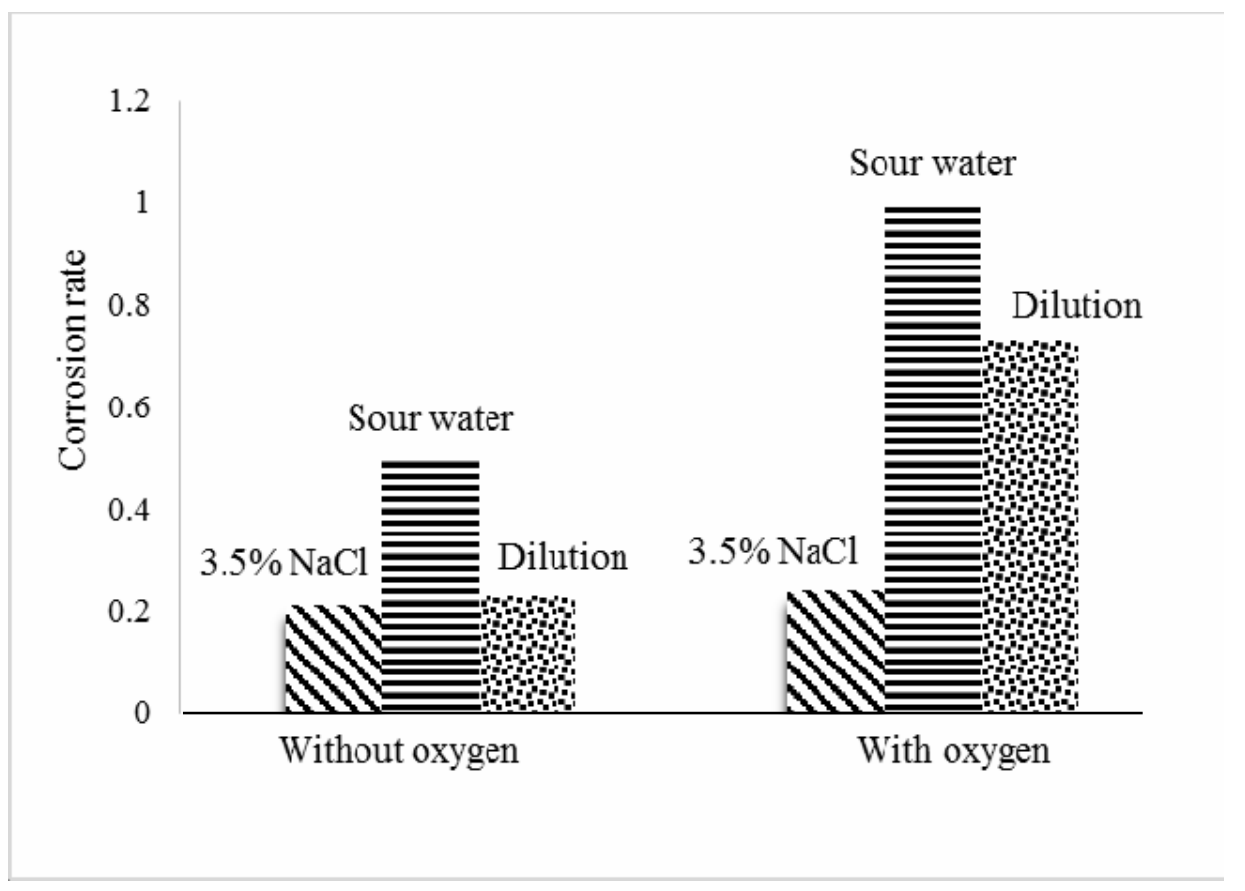

Fig. 2 - Comparison of corrosion rate with and without oxygen content 


\subsection{Structural and morphological studies}

Figure 3 presents the morphology of corrosion products before and after the immersion test in different medium by SEM. Localized corrosion product formed [8] on the surface of carbon steel before immersion in every medium (left). Meanwhile, after the immersion, the corrosion product formed to have identical character depending in every medium (right). A porous and honeycomb-like structure [9] found in $3.5 \% \mathrm{NaCl}$ (right) due to nucleation of chloride ion formed as solid crystal structure. However, corrosion product formed after immersion in sour water creates an irregular and cracking-like structure (figure 3 (b) right). High acidity contributes to dense precipitation of corrosion product. In dilution sour water, the corrosion product looks more porous compared to sour water and formed to have an irregular and stone-like structure in dilution of sour water.
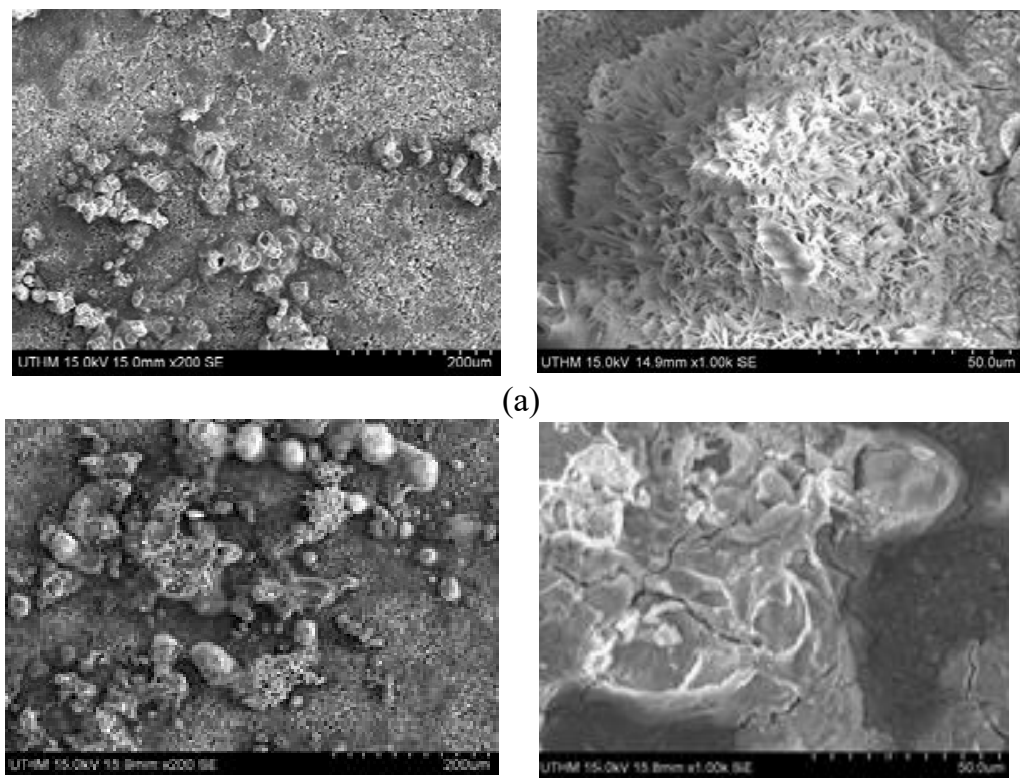

(a)
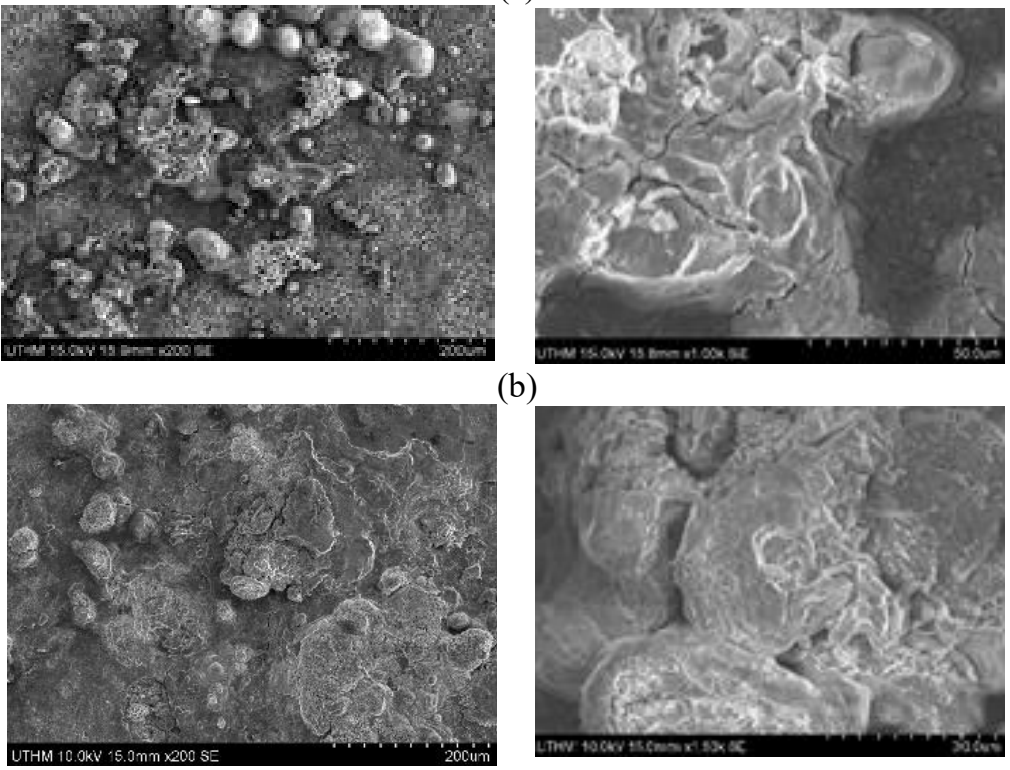

(b)

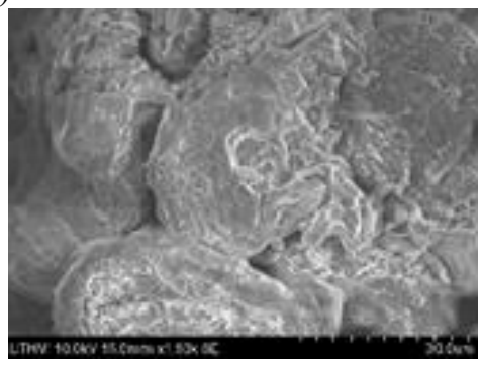

(c)

Fig. 3 - Corrosion product on the carbon steel immersed in (a) $3.5 \% \mathrm{NaCl}$, (b) sour water and (c) dilution of sour water

Chlorides carried downstream of crude units lead to deposition of sulfur in overhead. Routinely, neutralizers, such as ammonia $\left(\mathrm{NH}_{3}\right)$ and organic amines, are utilized in overhead systems for chloride control and to mitigate against acidic conditions of sulfur effect. This is a delicate task, and prone to misapplication, since under dosing leads to acid corrosion, while overdosing causes localized, under deposit corrosion when $\mathrm{NH}_{4} \mathrm{Cl}$, or amine- $\mathrm{HCl}$, precipitates before or above the water dew point.

\subsection{Elementary analysis}

Basically, corrosion reactions result in three ways namely immune, produce corrosion product or dissolution of base metal. By examining the corrosion product formed, a prediction of corrosion reactions can be identified. From the immersion test in sour water, the corrosion product formed in sour water was examined for the element which gives a reaction during corrosion attack. The list of elements detects by EDX shown in figure 4. Entirely, the corrosion product mostly composed of iron, oxygen, carbon, sodium and manganese.

The corrosion product formed on the carbon steel immersed in sour water was examined for element which gives a reaction during corrosion attack. The list of elements detects by EDX shown in figure 4. Entirely, the corrosion product mostly composed of iron, oxygen, carbon, sodium and manganese. Sulfur was found in sour water and diluted sour water, revealed that high corrosion attack was contribute by sulfur ion. These sulfur ions were collected during crude 
washing. The amount of sulfur also found in dilution of sour water which is much higher found in undiluted sour water. Therefore, it can be concluded, dilution proses could increase sulfur content which might be risk to overhead units.

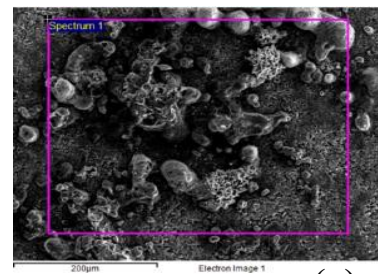

(a)
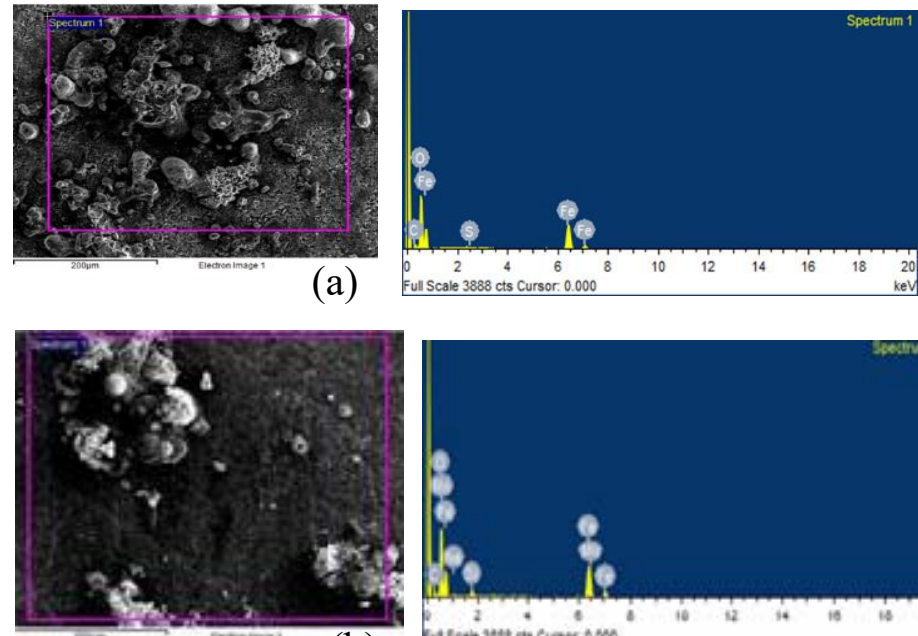

(b)
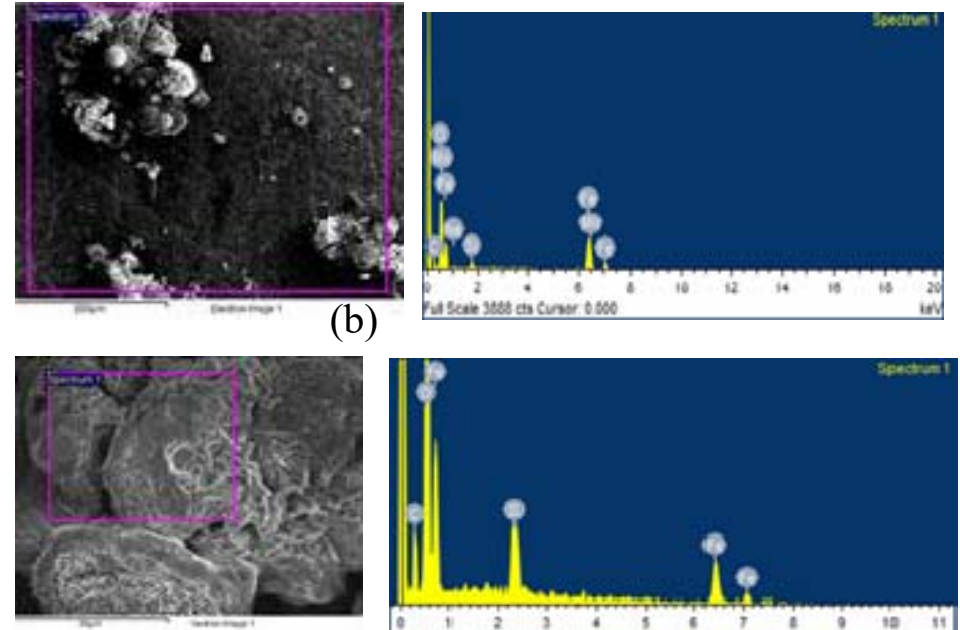

(c)

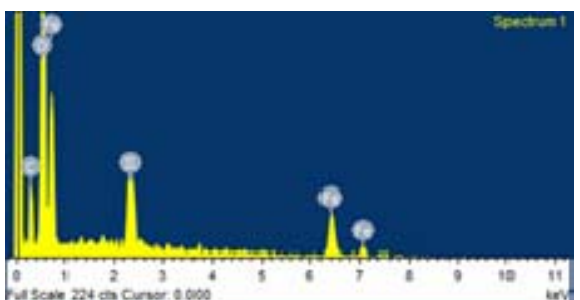

\begin{tabular}{|lll|}
\hline Elemen & Wt & Atomic \% \\
\hline $\mathrm{C}$ & 7.01 & 15.94 \\
$\mathrm{O}$ & 31.47 & 53.75 \\
$\mathrm{~S}$ & 0.59 & 0.51 \\
$\mathrm{Fe}$ & 60.93 & 29.81 \\
Totals & 100.0 & \\
\hline
\end{tabular}

\begin{tabular}{|lll|}
\hline Elemen & Wt & Atomic \% \\
\hline $\mathrm{C}$ & 7.56 & 17.01 \\
$\mathrm{O}$ & 30.62 & 51.72 \\
$\mathrm{Na}$ & 0.97 & 1.14 \\
$\mathrm{Si}$ & 1.44 & 1.39 \\
$\mathrm{Mn}$ & 0.95 & 0.47 \\
$\mathrm{Fe}$ & 58.46 & 28.28 \\
Totals & 100.0 & \\
\hline
\end{tabular}

\begin{tabular}{|ll|l|}
\hline Element & Wt \% & Atomic \% \\
\hline $\mathrm{C}$ & 8.49 & 17.26 \\
$\mathrm{O}$ & 37.59 & 57.36 \\
$\mathrm{~S}$ & 5.58 & 4.25 \\
$\mathrm{Fe}$ & 48.34 & 21.23 \\
Totals & 100.00 & \\
\hline
\end{tabular}

Fig. 4 - Composition of corrosion product on carbon steel surface immersed in (a) sour water (b) $3.5 \%$ $\mathrm{NaCl}$ and (c) in dilution of sour water

\subsection{Hardness test of AISI 1020 before and after corrosion attack}

Many researchers revealed that some correlation existed between hardness and corrosion. Some studies showed the corrosion resistance increased as the hardness increased due rearrangement and finer grain size [1 0-14]. By immersion test, carbon steel loss its hardness properties after corrosion attack on its surface. This is due to dissolution of electron once the carbon steel immersed in electrolyte. The chemical reactions was in activation polarization which contribute to significant of hardness effect [15]. Carbon steels reduced it hardness properties due to the corrosion attack especially when immersed in sour water sample followed by dilution sour water and $3.5 \% \mathrm{NaCl}$. Hardness found reduced in all solutions for immersion test with $\%$ reduction of $29.2 \%$ in sour water, $0.6 \%$ in $3.5 \% \mathrm{NaCl}$ and $3.5 \%$ reduction in dilution solution. Hardness depends on some characteristic microstructures, such as the grain size, the type of microstructure and the carbon content. Since the working electrode is only carbon steel, and no microstructure changed, therefore, the hardness value remained.

\section{Conclusion}

The properties of untreated sour water were initially measured to set a benchmark of results finding. Corrosion characterization was approached by identified the properties of corrosion product results by corrosion reaction. Immersion test was done to identify the metal loss due to exposure to sour water and diluted sour water. Characterization of sour water revealed that as-received sour water is not suitable to be used as wash water directly since its properties do not achieve the Petronas's Technical Standard for wash water. Immersion tests revealed the weight loss increased significantly with the time of immersion for all solutions. The corrosion attack more intense by sour water compared to dilution sour water and seawater in the electrochemical test. Reduction of hardness revealed the significant deterioration of mechanical properties due to corrosion attack even though some literature proved that corrosion does not affect hardness value. Characterization of corrosion product formed reveals that the chemical reaction contributes to the deterioration of carbon steel was attained by reaction of base metal with corrosiveness of sour water. The corrosion products formed have their own identical character depending in every medium. The elementary analysis revealed sulfur content which accelerate corrosion rate was attributed from contamination of sulfur during crude washing and the amount even increased in diluted sour water. Therefore, untreated sour water needs to be treated or inject with inhibitor for further use in CDU system. 


\section{Acknowledgement}

Authors wishing to acknowledge the registrar of Universiti Tun Hussein Onn Malaysia for funding of this publication and Research Management Centre (RMC) of Universiti Tun Hussein Onn Malaysia for their funding in TIER 1 U873 grant.

\section{References}

[1] K.Wang, B.J. Zhang, Q.L.Chen (2016). Optimization of a crude oil distillation unit based on total-process simulation. Computer Aided Chemical Engineering, 38, 2163-2168.

[2] Emerson (2017). Corrosion monitor solution for sour water stripping units. Petroleum Refining Industry 1-9

[3] L. Addington, C. Fitz, K. Lunsford, L. Lyddon, I. M. Siwek, and A. Gmbh (2103). Sour water: Where it comes from and how to handle it. Bryan Research and Engineering Inc. 1-17

[4] C. G. N. Mendes. (2012). Stripped Sour Water Treatment by Advanced Oxidation Processes 23(9) 1680- 1687

[5] R. H. Weiland and N. A. Hatcher. (2012). Sour water strippers exposed, Optim.Gas Treating.inc. 1-15

[6] J. and C. M. S. J. F. Mason (2012) Corrosion in sour water strippers NACE International 15

[7] NACE Standard Guide for Laboratory Immersion Corrosion Testing of Metals October 2012-2013

[8] A. B. Forero, I. S. Bott, and R. De Janeiro. (2014). Analysis of the Corrosion Scales Formed on API 5L X70 and X80 Steel Pipe in the Presence of CO2 17(2) 461-471

[9] L. S. A. Raman, S. Nasrazadani. (2014) Morphology of rust phases formed on weathering steels in various laboratory corrosion tests (22) 79-96

[10] Tjahjanti, P. H., Darminto, D., Nugroho, W. H., \& Ganda, A. N. (2019). Study of Corrosion Penetration Rate on Composite Materials. International Journal of Integrated Engineering, 11(6), 1-9.

[11] Ayop, S. S., \& Cairns, J. (2013). Critical Study of Corrosion Damaged Concrete Structures. International Journal of Integrated Engineering, 5(2):43-50.

[12] Sadikin, A., Mohd Bahrin, M. K. A., Ismail, A., Ismail, A. E., Ahmad, S., Md Salleh, S., Abdol Rahman, M. N., Sapit, A., \& Ayop, S. S. (2018). Numerical Simulation in Transient Flow of Non-Newtonian Fluid in Nozzles. International Journal of Integrated Engineering, 10(1):92-95.

[13] Yvette Shaan-Li, S., Abdul Rahim, R., Chiew Loon, G., Fazalul Rahiman, M. H., \& Abdul rahim, H. (2017). Intensity Profile Measurement for Carbon Steel Pipe using Gamma-Ray Tomography. International Journal of Integrated Engineering, 9(2).

[14] Abdulmalik, S. S., \& Ahmad, R. (2018). Influence of Friction Stir Process on Microstructure and Tensile Properties of LM28 Hypereutectic Al-Si Alloy. International Journal of Integrated Engineering, 10(3).

[15] I. Azzura, M.S.N. Farhana, M.N. Lokman et al. (2019) Identification corrosion hydrogen attack on carbon steel using magnetic particle inspection (MPI). Int. Conf. on Mech. Eng. Research and Application 494 1-8. 